\title{
Elemental Distribution in Fluorinated Amorphous Carbon Thin Films
}

\author{
A. Lamperti, ${ }^{*}$ C. E. Bottani, and P. M. Ossi \\ Dipartimento di Ingegneria Nucleare, and Centre of Excellence “Nano Engineered Materials and Surfaces \\ (NEMAS)," Politecnico di Milano, Milan, Italy
}

\begin{abstract}
Focused ion beam-secondary ion mass spectrometry (FIB-SIMS) with $20 \mathrm{~nm}$ spatial resolution has been used to analyze amorphous fluorinated carbon thin films, deposited by plasma assisted chemical vapor deposition (PACVD), at micro- to nano-scale. Mass spectra and ion imaging of film surface were acquired and the presence and distribution of contaminants were investigated. Surface images show the secondary ion distribution for $\mathrm{F}^{-}, \mathrm{CH}^{-}, \mathrm{CF}^{-}$. A change in size and topology of fluorine-rich areas is correlated with film hardness and with microstructure transition from diamond-like to polymer-like, as indicated by infrared and Raman spectroscopies. Based on the surface distributions of $\mathrm{CF}^{-}$and $\mathrm{CH}^{-}$and on the vibrational spectroscopy results, a mechanism of fluorine substitution for hydrogen and an attempt to explain the film structure and microstructure is proposed. (J Am Soc Mass Spectrom 2005, 16, 126-131) (C 2004 American Society for Mass Spectrometry
\end{abstract}

S ince the end of last century, fluorinated amorphous carbon films (a-C:F), mainly deposited by plasma assisted or enhanced chemical vapor deposition (PACVD-PECVD) have been used for many applications [1-4]. The physical properties of the $-\mathrm{CF}_{x}$ groups, which are a film constituent, permit a considerable reduction in friction and a substantial improvement in wear resistance, and confer a hydrophobic behavior to the film surface. Electronic applications of such a material are also foreseen because of the low value of the dielectric constant $k$ [5-14].

Several material properties (structural, chemical, mechanical, electrical, optical, etc.) have been studied as functions of process parameters [4, 12, 14-20], but a direct visualization of the surface element distribution is still lacking. We obtained a chemical surface image to reveal elements distributions, including contaminants and non-uniform elemental concentration. Such data can be used in conjunction with the other surface analysis results to gain a complete understanding of the film chemistry and structure.

We analyzed two samples, representative of a set of deposited films, synthesized by PACVD, starting from $\mathrm{C}_{2} \mathrm{H}_{2}$ and $\mathrm{CF}_{4}$, with different $\mathrm{CF}_{4}$ content in the plasma atmosphere, namely 33 and $71.4 \%$ of the total gas influx; the films have different micro-structure and hardness, as deduced from previous analyses $[19,20]$. In particular, vibrational spectroscopies [19] enabled determination of the amorphous nature of the films, the fraction of

Published online November 18, 2004

Address reprint requests to Dr. A. Lamperti, Nuclear Engineering Department, Politecnico di Milano, Via Ponzio 34-3, I-20133 Milano, Italy. E-mail: alessio.lamperti@polimi.it

* Also at The Enrico Fermi Institute, The University of Chicago, 5640 South Ellis Ave., Chicago, IL 60637, USA. $\mathrm{sp}^{2}$ and $\mathrm{sp}^{3}$ coordinated carbon atoms in the network and the presence of specific groups, specifically $-\mathrm{CF}_{\mathrm{x}}$. The features of Raman spectra were also correlated with film hardness, which was measured by micro-indentation [20]. Infrared and Raman spectroscopies clearly showed the formation of a partially hydrogenated fluorocarbon film, evolving from diamond-like to polymer-like behavior as the fluorine content increases in the gas mixture.

Focused ion beam secondary ions mass spectrometry (FIB-SIMS) is a unique technique for the visualization of the surface element distribution with high sensitivity and high resolution. It consists of a finely focused primary ion beam that scans and erodes a selected area on the sample surface. During the sputtering process, neutrals and secondary ions of the elements from the surface are ejected. These ions (both positive and negative) are extracted, accelerated in a mass spectrometer, detected by a multiplier detector, and, through a KONTRON IMCO controlling and image processing system, converted into a digital signal in order to generate an image on a screen, and stored for further analyses. Each image contains $512 \times 512$ picture elements from single square raster scan. This way, the scanning ion microprobe coupled with a high resolution mass spectrometer detects spatially resolved mass and intensity data. Many types of primary ion sources, mass spectrometers, and geometry have been explored in the past decades in the construction of SIMS instruments and further details can be found in the widespread literature [21, 22].

We obtained a series of images of element distribution along the film surface for each sample, with 50 nm lateral resolution, that show a qualitative change in size and topology of fluorine-rich areas. The im- 


\begin{tabular}{|c|c|c|c|c|c|c|c|}
\hline peak \# & ion & peak \# & ion & peak \# & ion & peak \# & ion \\
\hline 1 & $\mathrm{C}^{-}$ & 5 & $\mathrm{~F}$ & 9 & $\mathrm{CF}^{-}$ & 13 & ${ }^{37} \mathrm{Cl}^{-}$and $\mathrm{C}_{3} \mathrm{H}^{-}$ \\
\hline 2 & $\mathrm{CH}^{-}$ & 6 & $\mathrm{C}_{2}^{-}$ & 10 & $\mathrm{O}_{2}^{-}$ & 14 & $\mathrm{C}_{4}^{-}$ \\
\hline 3 & $\mathrm{O}^{-}$ & 7 & $\mathrm{C}_{2} \mathrm{H}^{-}$ & 11 & ${ }^{35} \mathrm{Cr}^{-}$ & 15 & $\mathrm{C}_{4} \mathrm{H}^{-}$ \\
\hline 4 & $\mathrm{OH}^{-}$ & 8 & $\mathrm{CN}^{-}$and $\mathrm{C}_{2} \mathrm{H}_{2}$ & 12 & $\mathrm{C}_{3}^{-}$ & 16 & $\mathrm{CF}_{2}{ }^{-}$and $\mathrm{C}_{4} \mathrm{H}_{2}$ \\
\hline
\end{tabular}

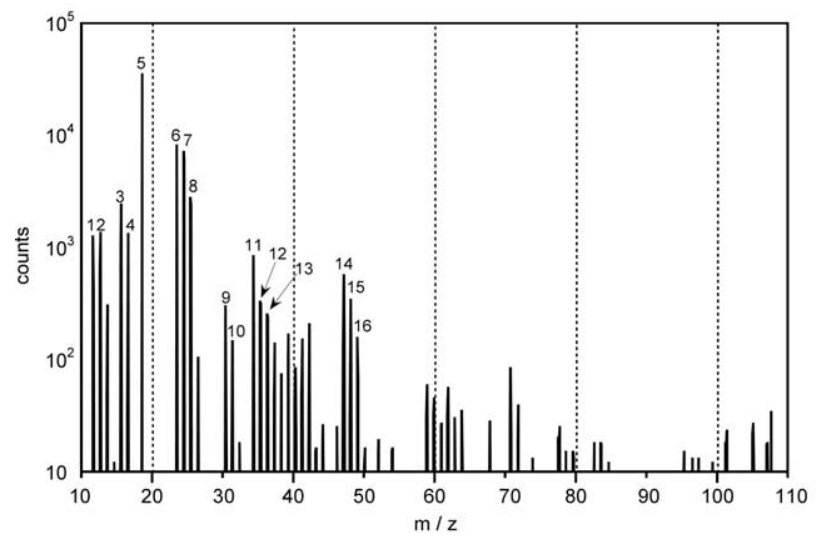

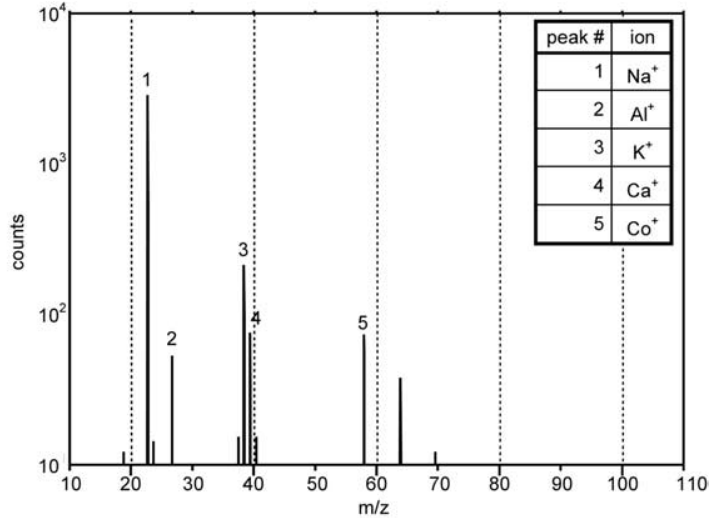

(b)

(a)

Figure 1. Mass spectrum of fluorinated amorphous carbon film deposited with $33 \% \mathrm{CF}_{4}$ content in the gas mixture: negative (a) and positive (b) ions spectrum. $\mathrm{X}$ axis, mass/charge; $\mathrm{Y}$ axis, counts.

ages presented here are representative of areas that are easily found along the film surface.

\section{Experimental}

Films were deposited in a DC-PACVD cylindrical reactor $4 \mathrm{dm}^{3}$ in volume at an operating pressure of about 1 $\mathrm{Pa}$, at room temperature. The gas ratio between $\mathrm{C}_{2} \mathrm{H}_{2}$ and $\mathrm{CF}_{4}$ (33 or $71 \%$ in $\mathrm{CF}_{4}$ ) was independently controlled by two flux-meters. An independent power supply provided a bias voltage $\mathrm{V}_{\mathrm{b}}=-250 \mathrm{~V}$ to the substrate. A solenoid placed on the back of the source generated a $0.1 \mathrm{~T}$ magnetic field to improve plasma confinement to the substrate surface. Films about $1 \mu \mathrm{m}$ thick were deposited on widia (sintered WC- $8 \% \mathrm{Co}$ ) substrates, previously polished and smoothed. A detailed description of the deposition apparatus can be found in references [20, 23]. As a result of the deposition process an amorphous hydrogenated and fluorinated carbon film is formed.

FIB-SIMS, or scanning ion probe secondary ion mass spectrometry, installed at The University of Chicago (UofC) is capable of $20 \mathrm{~nm}$ lateral resolution, attributable to a finely focused $40 \mathrm{keV}, 35 \mathrm{pA} \mathrm{Ga}{ }^{+}$primary ion beam; the ion flux density is about $10^{18}$ ions $\mathrm{cm}^{-2} \mathrm{~s}^{-1}$. In the present SIMS analyses, we choose a spot size with a diameter of $50 \mathrm{~nm}$, intended as the full width at half maximum of the beam conical shape (Taylor cone), thus defining the lateral resolution [24]. During the single raster scan the nanofocused primary ion beam dwells for 100-200 $\mu$ s on the sampled area. Thus the number of primary ions impinging onto the portion of the surface illuminated by the beam spot is roughly $2 \times 10^{3}$ per single raster scan. A pressure value of $10^{-6} \mathrm{~Pa}$, or lower, in the machine main chamber is required for an optimal working condition; in the present experiments the pressure value was around $10^{-7} \mathrm{~Pa}$. The machine has ppm sensitivity for all elements, and ppb sensitivity for light, alkali and halide elements. Secondary ions are collected and then detected by a magnetic sector mass spectrometer with mass resolution, $\mathrm{m} / \Delta \mathrm{m}$, of about 2000 [24, 25]. We collected mass spectra in the $\Delta \mathrm{m} 10-110 \mathrm{~m} / \mathrm{z}$ range, both for negative and positive secondary ions besides recording surface images for the distribution of $\mathrm{CH}^{-}$, $\mathrm{F}^{-}, \mathrm{CF}^{-}$groups; the pictures were taken over film areas of different size. The experiment was performed under dynamic conditions.

\section{Results}

Mass spectra clearly show strong intensity for carbon $\left(\mathrm{C}_{2}^{-}\right)$and fluorine $\left(\mathrm{F}^{-}\right)$in both films, as shown in Figure 1a and Figure 2a, respectively, for the films deposited with $\mathrm{CF}_{4} 33$ and $71.4 \%$ of the total gas flux. Peaks related to $\mathrm{CH}^{-}, \mathrm{C}_{2} \mathrm{H}^{-}, \mathrm{CF}^{-}, \mathrm{CF}_{2}^{-}$ions, among other carbon compounds, are visible. Peaks from atmospheric contaminants, such as $\mathrm{Na}^{+}, \mathrm{Al}^{+}, \mathrm{K}^{+}, \mathrm{Ca}^{+},{ }^{35} \mathrm{Cl}^{-}$(and $\left.{ }^{37} \mathrm{Cl}^{-}\right)$, are also present, as shown in Figure $1 \mathrm{~b}$ and Figure 2b, respectively, for the films deposited with $\mathrm{CF}_{4}$ 33 and $71.4 \%$ of the total gas flux content in gas plasma. In fact, due to sample exposure to the atmosphere, the surface easily adsorbs such contaminants that are likely to distribute almost randomly along the surface.

Mass spectra show that carbon, fluorine, and hydrogen are the main film constituents, showing both elemental ions and groups such as $\mathrm{C}_{n} \mathrm{H}^{-}$and $\mathrm{CF}_{\mathrm{x}}{ }^{-}$. The 


\begin{tabular}{|c|c|c|c|c|c|c|c|}
\hline peak\# & ion & peak\# & ion & peak \# & ion & peak\# & ion \\
\hline 1 & c & 6 & $\mathrm{C}_{2}$ & 11 & ${ }^{35} \mathrm{Cr}$ & 16 & $\mathrm{C}_{4} \mathrm{H}^{\circ}$ \\
\hline 2 & $\mathrm{CH}^{-}$ & 7 & $\mathrm{C}_{2} \mathrm{H}^{-}$ & 12 & $\mathrm{C}_{3}^{-}$ & 17 & $\mathrm{CF}_{2}$ and $\mathrm{C}_{4} \mathrm{H}_{2}$ \\
\hline 3 & 0 & 8 & $\mathrm{CN}^{\prime}$ and $\mathrm{C}_{2} \mathrm{H}_{2}$ & 13 & ${ }^{37} \mathrm{Cr}$ and $\mathrm{C}_{3} \mathrm{H}^{-}$ & 18 & $\mathrm{C}_{5}^{-}$ \\
\hline 4 & $\mathrm{OH}^{-}$ & 9 & $\mathrm{CF}$ & 14 & 43 & 19 & $\mathrm{C}_{6}^{-}$ \\
\hline 5 & $\mathrm{~F}$ & 10 & $\mathrm{O}_{2}$ and $\mathrm{CFH}^{-}$ & 15 & $\mathrm{C}_{4}^{-}$ & 20 & ${ }^{103}\left(\mathrm{CF}_{4}{ }^{\circ} \mathrm{CH}_{3}\right)^{-}$ \\
\hline
\end{tabular}

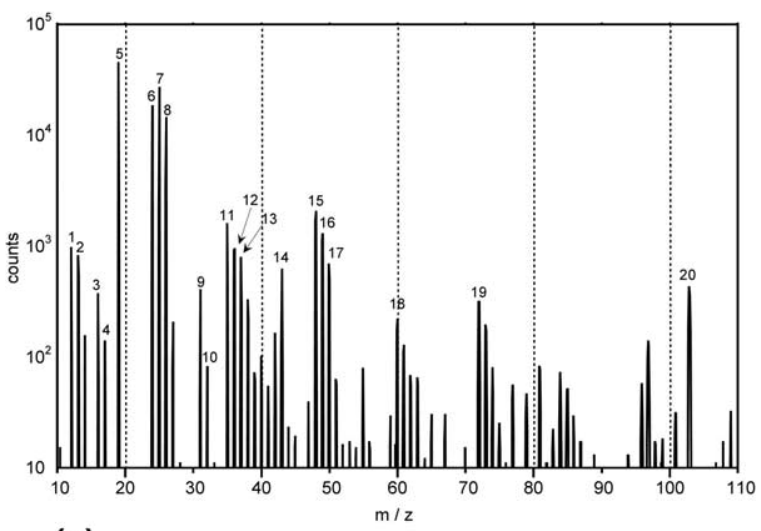

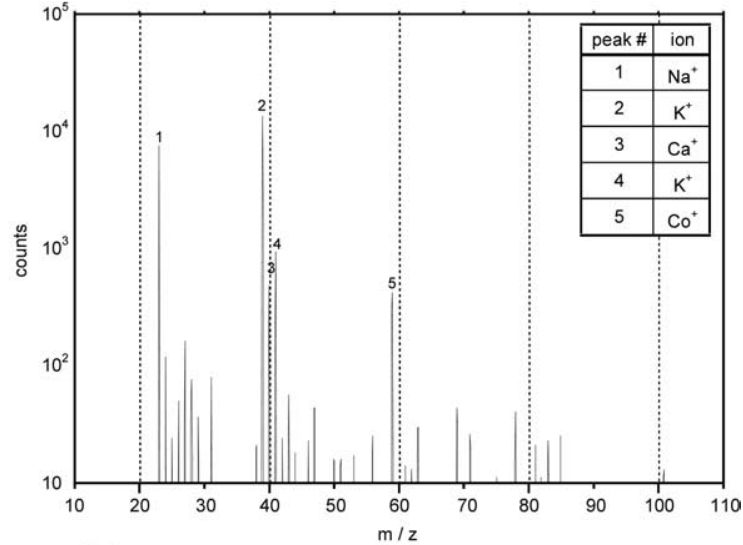

(b)

(a)

Figure 2. Mass spectrum of fluorinated amorphous carbon film deposited with $71.4 \% \mathrm{CF}_{4}$ content in the gas mixture: negative (a) and positive (b) ions spectrum. $\mathrm{X}$ axis, mass/charge; $\mathrm{Y}$ axis, counts.

peak ratios $\mathrm{F}^{-} / \mathrm{C}^{-}, \mathrm{F}^{-} / \mathrm{CH}^{-}$, and $\mathrm{CH}^{-} / \mathrm{C}^{-}$from the two films show that the film produced with higher $\mathrm{CF}_{4}$ content in the plasma has higher fluorine content in its matrix and, at the same time, it is hydrogen depleted. Table 1 summarizes the calculated ratios for both samples. Each ion ratio is calculated from the intensities of the pertinent spectral lines; each spectrum was collected from a single scansion over a $40 \times 40 \mu \mathrm{m}^{2}$ area.

In Figure 3 fluorine $\left(\mathrm{F}^{-}\right)$distribution is shown. The left picture refers to the film with low fluorine content; the right picture refers to the film with high fluorine content. Both pictures are greyscale, 255 levels, from black (no fluorine) to white (fluorine-richest) areas. An evident change in the size of fluorine-rich areas appears. They are smaller and not connected to each other in the film deposited at low $\mathrm{CF}_{4}$ content, while in the presence of high $\mathrm{CF}_{4}$ content the comparatively larger fluorine-rich areas percolate through the film. Moreover, from the greyscale value of each point in the figure we calculated the average ratio between areas rich or respectively poor in fluorine. We obtained a value of 1.47 for the picture on the left and 1.98 for the picture on the right; both values indicate fluorine enrichment in some areas of the film. Further, the ratio

Table 1. Calculated ratios from $\mathrm{C}^{-}, \mathrm{CH}^{-}, \mathrm{F}^{-}$peaks on mass spectra for both films. Data show a remarkably higher fluorine and lower hydrogen content in the film deposited with $71.4 \%$ $\mathrm{CF}_{4}$ in gas mixture with respect to the film deposited with $33 \%$ $\mathrm{CF}_{4}$ in gas mixture

\begin{tabular}{cccr}
\hline $\mathrm{CF}_{4}$ content & $\mathrm{F}^{-} / \mathrm{C}^{-}$ & $\mathrm{F}^{-} / \mathrm{CH}^{-}$ & $\mathrm{CH}^{-} / \mathrm{C}^{-}$ \\
\hline \hline $33 \%$ & 27.596 & 25.678 & 1.074 \\
$71.4 \%$ & 49.200 & 58.162 & 0.846 \\
\hline
\end{tabular}

between the above two values, namely $1.98 / 1.47=$ 1.347 , is much less than the nominal calculated ratio from the inlet gas mixture, namely $0.714 / 0.33=2.164$. This suggests that, in the reactor chamber, fluorine is partially not involved in the reactions leading to film growth.

Figure 4 shows a detail of the film deposited from a gas mixture with $33 \% \mathrm{CF}_{4}$ content and the surface distributions for $\mathrm{CH}^{-}$and $\mathrm{CF}^{-}$. The areas indicated by boxes are the same in both pictures: in the left image the white coloration of the selected areas corresponds to high $\mathrm{CH}^{-}$content. In the right image the same areas appear darker. Indeed, $\mathrm{CF}^{-}$presence is now looked for and such a group is shown as white color.

\section{Discussion}

When $\mathrm{CF}_{4}$ is a small fraction of the total gas flux (33\% in our case), a small amount of free fluorine and $\mathrm{CF}_{\mathrm{x}}$ radicals in the deposition chamber is available to form these cluster and small fluorine-rich regions found on the film surface, attributable to the low flux of the fluorocarbon feeding gas. The film behavior is typical of a hydrogenated, partially fluorinated, diamond-like, amorphous carbon (DLC) film [4, 20, 26]. Conversely, in a $\mathrm{CF}_{4}$-rich plasma (71.4\% of total gas flux), free fluorine and $\mathrm{CF}_{\mathrm{x}}$ radicals are present in a consistent amount in the deposition chamber. Infrared (Figure 5) and Raman (Figure 6) spectra show that the fluorine-rich areas mainly consist of $\mathrm{CF}_{2}$ and $\mathrm{CF}_{3}$ cluster chains with polymeric character, produced during the deposition process in the gas plasma. Infrared spectroscopy clearly shows the presence of $-\mathrm{CF}_{\mathrm{x}}(\mathrm{x}=1,2,3), \mathrm{C}=\mathrm{CHF}$, and $\mathrm{C}=\mathrm{CF}_{2}$ groups in the film produced with $71.4 \% \mathrm{CF}_{4}$ in 

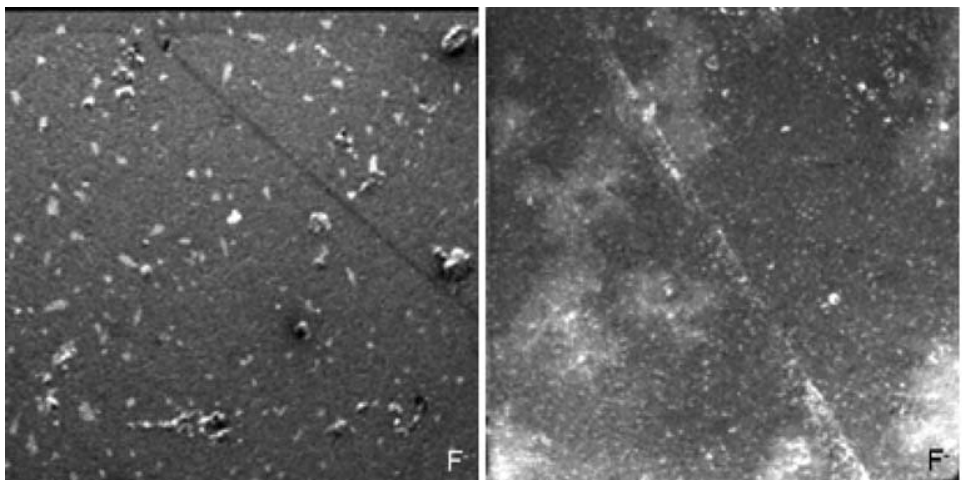

Figure 3. Surface images of fluorine $\left(\mathrm{F}^{-}\right)$distribution in fluorinated amorphous carbon films. Left: 40 $\times 40 \mu \mathrm{m}^{2}$ area from the film deposited with $33 \% \mathrm{CF}_{4}$ in gas mixture; right: $80 \times 80 \mu \mathrm{m}^{2}$ area from the film deposited with $71.4 \% \mathrm{CF}_{4}$ in gas mixture.

the gas mixture. The Raman features of amorphous carbon films, namely the D and G bands, are evident in the corresponding spectrum; the strong background indicates that the film has a high polymeric content [27]. Fluorine-rich areas on the film surface grow in size and become interconnected with each other (see Figure 3). Precisely such areas control film properties, leading to a highly polymeric film, as confirmed by infrared spectroscopy and micro-hardness measurements $[19,20]$. Furthermore, our deposition conditions support the formation of volatile hydrofluoric acid, $\mathrm{HF}$, providing a channel for hydrogen elimination.

A competition between the two elements begins with the introduction of fluorine in hydrogen plasma. A low fluorine content does not affect film formation and a fluorine-free a-C:H film is obtained, provided pressure and bias voltage values corresponding to about $100 \mathrm{eV}$ ion $^{-1}$ are met, in agreement with the sub-plantation model [28].

Increasing fluorine content in the plasma, the relative fraction of free $\mathrm{F}^{-}$and $\mathrm{CF}_{3}{ }^{+}$radicals, or ions, increases because of the dominant plasma reaction: $\mathrm{CF}_{4} \rightarrow \mathrm{CF}_{4}{ }^{*} \rightarrow$ $\mathrm{CF}_{3}{ }^{+}+\mathrm{F}^{-}$, where $\mathrm{CF}_{4}{ }^{*}$ indicates a metastable excited $\mathrm{CF}_{4}$ state. $\mathrm{CF}_{3}{ }^{+}$substitutes in the carbon network for hydrogen-carbon groups, such as $\mathrm{CH}_{3}{ }^{+}$. Simultaneously, free fluorine substitutes for hydrogen in saturating dangling bonds, attributable to the fluorine higher electron affinity with respect to hydrogen. Given the larger size of fluorine ions with respect to hydrogen ions, we speculate that the process occurs whenever sites of suitable shape and size are available to accept fluorine ions. The resulting film has fluorine-rich areas at nano- or micro-scale and the cross-linked carbon network is affected by the presence of such fluorine-rich areas. In fact, film hardness is lower than that of fluorine-free films [20]. Yet, the film is hard enough to be classified as a DLC film. The structure of a pure DLC film consists of a carbon network, where the highly variable ratio of $\mathrm{sp}^{3}$ to $\mathrm{sp}^{2}$ in carbon bond coordination depends mainly on the synthesis method and on the process parameters. When other elements are added into the deposition plasma (e.g., hydrogen, nitrogen, fluorine,...) they affect the film structure and a hydro-carbon or nitro-hydro-carbon or fluoro-hydro-carbon network is formed. A detailed description of DLC film structure, microstructure, and properties can be found in [4].

A further increase in $\mathrm{CF}_{4}$ inlet in the reactor leads to a plasma excessively enriched in fluorine. A film deposited in these conditions consists of big fluorine-rich areas partially embedded in carbonaceous regions, thus becoming almost completely polymer-like.
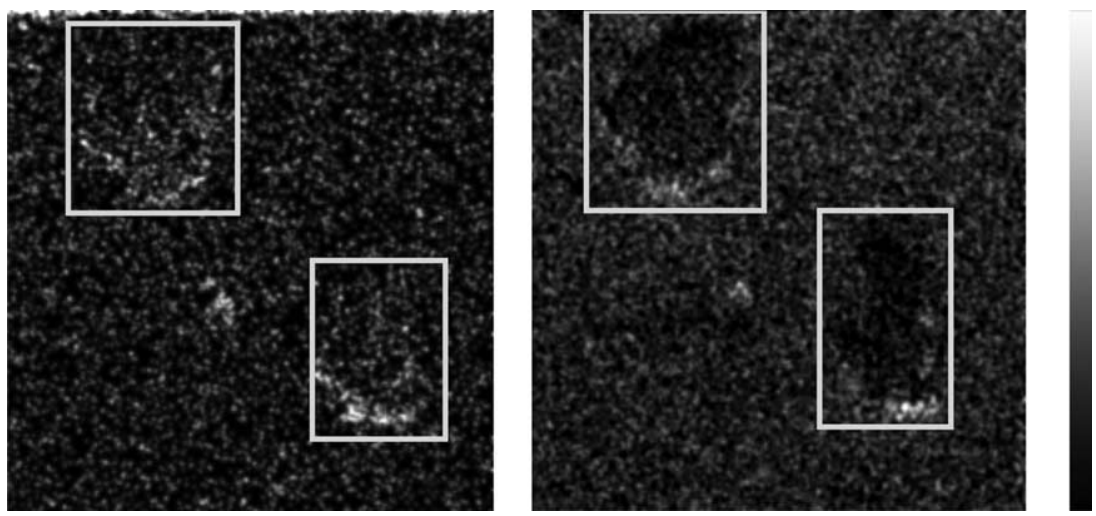

Figure 4. Images of $\mathrm{CH}^{-}$(left) and $\mathrm{CF}^{-}$(right) distributions from the same area of the film deposited with $33 \% \mathrm{CF}_{4}$ in gas mixture; $20 \times 20 \mu \mathrm{m}^{2}$ area; lateral resolution $50 \mathrm{~nm}$. 


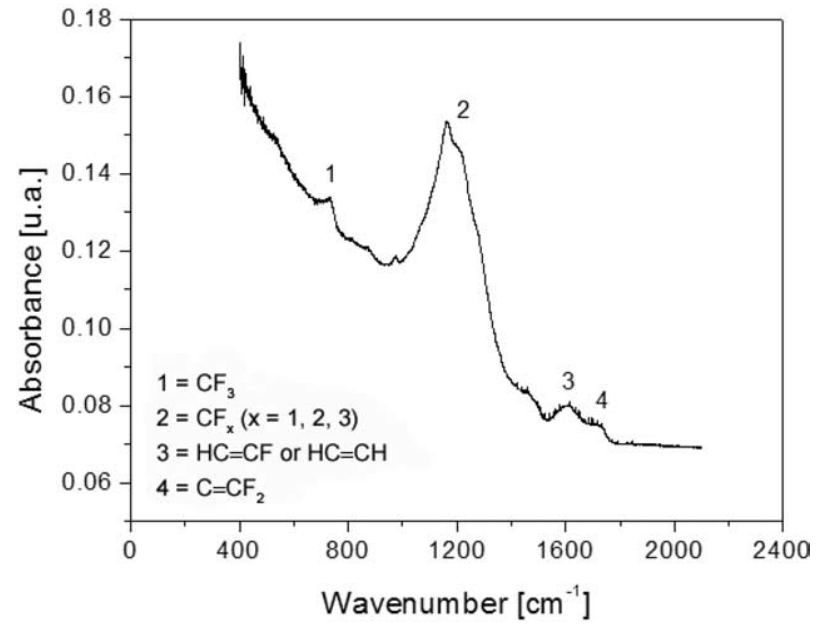

Figure 5. Infrared spectrum of the film deposited with $71.4 \% \mathrm{CF}_{4}$ in gas mixture. The spectral lines associated to the different fluorine groups are indicated.

The areas in Figure 4 show at high resolution a detail of film surface, allowing for a direct observation of the chemistry of the film surface. In particular it is possible to discriminate between regions where the $\mathrm{CF}^{-}$enriched areas appear depleted in $\mathrm{CH}^{-}$and vice versa, along with areas where both species coexist and regions where both of them are absent. These images confirm the simple formation mechanism of fluorinated amorphous carbon films; during the out-of-equilibrium film growth, small aggregates of atoms containing $\mathrm{CF}_{x}$, or $\mathrm{CH}_{n}$, or a mixture of both, are produced on the film surface. Subsequently, such aggregates join both by direct linking among each other and by interconnecting to the carbon backbone network, which is developing in the film at the same time. Consequently, in the high resolution surface

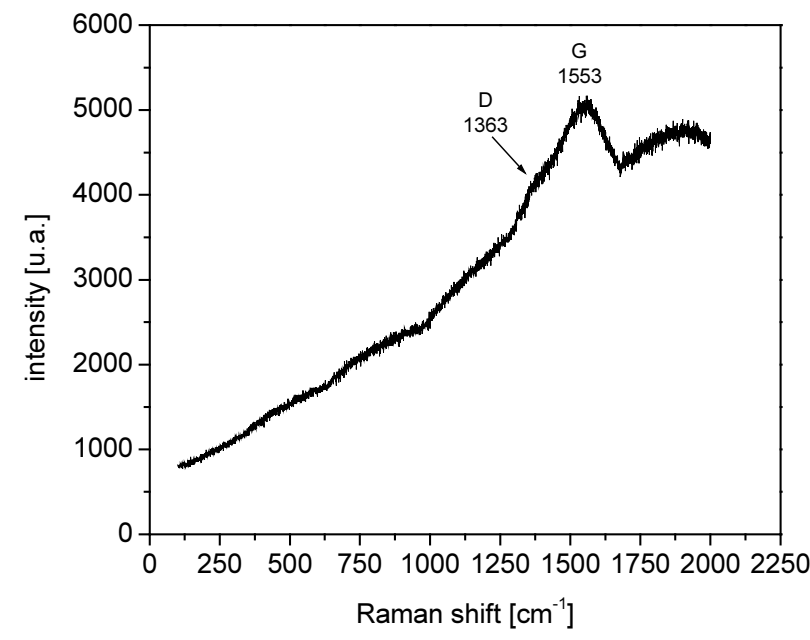

Figure 6. Raman spectrum for the film deposited with $71.4 \% \mathrm{CF}_{4}$ in gas mixture. The $\mathrm{D}$ and $\mathrm{G}$ bands and the strong background are typical features of a highly polymeric amorphous fluorinated carbon film.
SIMS maps, some areas appear rich only in fluorine $\left(\mathrm{CF}^{-}\right)$, or in hydrogen $\left(\mathrm{CH}^{-}\right)$, or in both.

\section{Conclusions}

In conclusion, by FIB-SIMS analyses we identified the existing elements into a-C:F films, together with their distribution along the film surface. By monitoring $\mathrm{CF}^{-}$and $\mathrm{CH}^{-}$we obtained images of surface element distribution in agreement with a proposed mechanism of fluorine substitution for hydrogen, that governs a-C:F film formation and growth, as well as film structure and properties.

\section{Acknowledgments}

The authors are grateful to Drs. L. Nobili and L. Brambilla, Department of Chemistry, Materials and Industrial Chemistry G. Natta, Politecnico di Milano, for their help with film deposition and hardness and infrared analyses. FIB-SIMS measurements in Chicago were supported by the G. Harold and Leyla Y. Mathers Charity Foundation. AL acknowledges financial support by Lombardy Industrial Union Assolombarda.

\section{References}

1. Jiang, X.; Zou, J. W.; Reichelt, K.; Grunberg, P. The Study of Mechanical Properties of a-C: H Films by Brillouin Scattering and Ultralow Load Indentation. J. Appl. Phys. 1989, 66, 47294735.

2. Jiang, X.; Reichelt, K.; Stritzker, B. Mechanical Properties of a-C: H Films Prepared by Plasma Decomposition of $\mathrm{C}_{2} \mathrm{H}_{2}$. J. Appl. Phys. 1990, 68, 1018-1022.

3. Jiang, X.; Reichelt, K; Stritzker, B. The Hardness and Young's Modulus of Amorphous Hydrogenated Carbon and Silicon Films Measured with an Ultralow Load Indenter. J. Appl. Phys. 1989, 66, 5805-5808.

4. Robertson, J. Diamond-Like Amorphous Carbon. Mater. Sci. Eng. 2002, R271, 1-153.

5. Kudo, H.; Takeishi, S.; Shinohara, R.; Yamada, M. Characteristics of Plasma C-F Films for Very Low-k Dielectrics. Proceedings of the Third International Dielectrics for ULSI Multilevel Interconnection Conference, (DUMIC); Santa Clara, CA, 1997; pp 85-92.

6. Labelle, C. B.; Limb, S. J.; Gleason, K. K. Characterization of Pulse-Plasma Enhanced Chemical Vapor Deposited Fluorocarbon Thin Film. Proceedings of the Third International Dielectrics for ULSI Multilevel Interconnection Conference, (DUMIC); Santa Clara, CA, 1997; pp 98-105.

7. Yokomichi, H.; Hayashi, T.; Masuda, A. Changes in Structure and Nature of Defects by Annealing of Fluorinated Amorphous Carbon Thin Films with Low Dielectric Constant. Appl. Phys. Lett. 1998, 72, 2704-2706.

8. Chowalla, M.; Robertson, J.; Chen. W. C.; Silva, S. R. P.; Davis, C. A.; Amaratunga, G. A. J.; Milne, W. I. Influence of Ion Energy and Substrate Temperature on the Optical and Electronic Properties of Tetrahedral Amorphous Carbon (ta-C) Films. J. Appl. Phys. 1997, 81, 139-145.

9. Racine, B.; Benlahsen, M.; Zellama, K; Bouzerar, R.; Kleider, J. P.; Von Bardeleben, H. J. Electronic Properties of Hydrogenated Amorphous Carbon Films Deposited Using ECR-RF Plasma Method. Diamond Relat. Mat. 2001, 10, 200-206.

10. Biswas, N.; Harris, H. R.; Wang, X.; Celebi, G.; Temkin, H.; Gangopadhyay, S. Electrical Properties of Fluorinated Amorphous Carbon Films. J. Appl. Phys. 2001, 89, 4417-4421. 
11. Theil, J. A. Fluorinated Amorphous Carbon Films for Low Permittivity Interlevel Dielectrics. J. Vac. Sci. Technol. B 1999, 17, 2397-2410.

12. Yokomichi, H.; Masuda, A. Effect of Sputtering with Hydrogen Dilution on Fluorine Concentration of low Hydrogen Content Fluorinated Amorphous Carbon Thin Films with Low Dielectric Constant. J. Appl. Phys. 1999, 86, 2468-2472.

13. Yang, H.; Tweet, D. J.; Ma, Y.; Nguyen, T. Deposition of Highly Crosslinked Fluorinated Amorphous Carbon Film and Structural Evolution During Thermal Annealing. Appl. Phys. Lett. 1998, 73, 1514-1516.

14. Endo, K.; Shinoda, K.; Tatsumi, T. Plasma Deposition of Low-Dielectric-Constant Fluorinated Amorphous Carbon. J. Appl. Phys. 1999, 86, 2739-2745.

15. Jacobsohn, L. G.; Franceschini, D. F.; Maia da Costa, M. E. H.; Freire, F. L., Jr. Structural and Mechanical Characterization of Fluorinated Amorphous-Carbon Films Deposited by Plasma Decomposition of $\mathrm{CF}_{4}-\mathrm{CH}_{4}$ Gas Mixtures. J. Vac. Sci. Technol. A 2000, 18, 2230-2238.

16. Valentini, L.; Braca, E.; Kenny, J. M.; Lozzi, L.; Cantucci, S. Influence of Plasma Source Frequency on Composition and Density of Fluorinated Amorphous Carbon Thin Films. Mater. Lett. 2001, 51, 514-518.

17. Yu, G. Q.; Tay, B. K.; Sun, Z.; Pan, L. K. Properties of Fluorinated Amorphous Diamond-Like Carbon Films by PECVD. Appl. Surf. Sci. 2003, 219, 228-237.

18. Wang, X.; Harris, H.; Temkin, H.; Gangopadhyay, S.; Strathman, M. D.; West, M. Determination of Oscillator Strength of C-F Vibrations in Fluorinated Amorphous-Carbon Films by Infrared Spectroscopy. Appl. Phys. Lett. 2001, 78, 3079-3081.

19. Lamperti, A.; Ossi, P. M. Systematic Study of Amorphous Hydrogenated and Fluorinated Carbon Films. Appl. Surf. Sci. 2003, 205, 113-120.
20. Bottani, C. E.; Lamperti, A.; Nobili, L.; Ossi, P. M. Structure and Mechanical Properties of PACVD Fluorinated Amorphous Carbon Films. Thin Solid Films 2003, 433, 149-154.

21. Briggs, D; Brown, A; Vickerman, J. C. Handbook of Static Secondary Ion Mass Spectrometry; John Wiley and Sons: New York, 1989, pp 1-156.

22. Benninghoven, A.; Rüdenauer, F. G.; Werner, H. W. Secondary Ion Mass Spectroscopy. In Basic concepts, Instrumental Aspects, Applications and Trends; Elving, P. J.; Winefordner, J. D., Eds; John Wiley and Sons: New York, 1987, pp 1-1264.

23. Nobili, L.; Cavallotti, P. L., Coccia Lecis, G.; De Ponti, G.; Lenardi, C. a-C(:H) and a- $\mathrm{CN}_{x}(: \mathrm{H})$ Films Deposited by Magnetron Sputtering and PACVD. Thin Solid Films 1998, 317, 359-362.

24. Chabala, J. M.; Soni, K. K.; Li, J.; Gavrilov, K. L.; Levi-Setti, R. High-Resolution Chemical Imaging with Scanning Ion Probe SIMS. Intl. J. Mass Spectrom. Ion Processes 1995, 143, 191-212.

25. Levi-Setti, R.; Gavrilov, K. L. High Resolution Secondary Ion Mass Spectroscopy Imaging. In Encyclopedia of Imaging and Technology; Hornak, J. P., Ed.; John Wiley and Sons: New York, 2002; pp 477-491.

26. Ferrari, A. C.; Robertson, J. Interpretation of Raman Spectra of Disordered and Amorphous Carbon. Phys. Rev. B 2000, 61, 14095-14107.

27. D'Agostino, R.; Lamendola, R.; Favia, P.; Giquel, A. Fluorinated Diamond-Like Carbon Films Deposited from Radio Frequency Glow Discharge in a Triode Reactor. J. Vac. Sci. Technol. A 1994, 12, 308-313.

28. Lifshitz, Y.; Kasi, S. R.; Rabalais, J. W.; Eckestein, W. Subplantation Model for Film Growth from Hyperthermal Species. Phys. Rev. B 1990, 41, 10468-10480. 